\title{
Factor Structure of the Clinician-Rated Dimensions of Psychosis Symptom Severity in Patients with Schizophrenia
}

\author{
Seon-Cheol Park ${ }^{1}$, Kang Uk Lee ${ }^{2}$, and Joonho Choi ${ }^{3,4} \bowtie$ \\ ${ }^{1}$ Department of Psychiatry, Inje University Haeundae Paik Hospital, Busan, Republic of Korea \\ ${ }^{2}$ Department of Psychiatry, Kangwon University School of Medicine, Chuncheon, Republic of Korea \\ ${ }^{3}$ Department of Psychiatry, Hanyang University Guri Hospital, Guri, Republic of Korea \\ ${ }^{4}$ Department of Psychiatry, Hanyang University College of Medicine, Seoul, Republic of Korea
}

DSM-5 has proposed the use of the Clinician-Rated Dimension of Psychosis Symptom Severity (CRDPSS) for evaluating the various symptoms of schizophrenia. ${ }^{1}$ The 8 -domain CRDPSS was developed from the perspective of deconstructing the psychopathology of schizophrenia and would be expected to provide baseline data for further advances in psychiatric nosology. In considering trends in psychiatric nosology, Panas ${ }^{3}$ has suggested that phenomenological Gestalt has faded into oblivion in the diagnostic criteria for schizophrenia and that psychiatric nosology has regressed to a pre-Kraepelinian state. To our knowledge, despite these discussions, the dimensional structure of the CRDPSS has hardly been studied.

We therefore aimed to identify the factor solution of the CRDPSS. As described elsewhere, ${ }^{4} 166$ in patients with schizophrenia (diagnosed with the DSM-5), ${ }^{5}$ age $\geq 18$ years and $\leq 65$ years, and length of hospital stay $\geq 2$ weeks were recruited in Korea. Half were men (51.5\%). Their mean age and age at onset were $46.5(\mathrm{SD}=11.2)$ and $25.2(\mathrm{SD}=13.2)$ years, respectively, and the mean chlorpromazine equivalent dose of antipsychotic prescriptions was $921.1(\mathrm{SD}=952.0) \mathrm{mg}$.

Mean scores on the hallucinations, delusions, disorganized speech, abnormal psychomotor behaviors, negative symptoms, impaired cognition, depression and mania were 2.04 ( $\mathrm{SD}=1.30), 2.27(\mathrm{SD}=1.16), 1.62(\mathrm{SD}=1.35), 1.16(\mathrm{SD}=1.16)$, $2.01(\mathrm{SD}=1.24), 1.22(\mathrm{SD}=1.22), 0.51(\mathrm{SD}=0.70)$ and $0.19(\mathrm{SD}=$ 0.48 ), respectively. An exploratory factor analysis (EFA) was conducted on the CRDPSS, with principle components ex-

Received: August 24, 2015 Revised: November 12, 2015

Accepted: November 12, 2015 Available online: November 18, 2015

$\triangle$ Correspondence: Joonho Choi, MD, PhD

Department of Psychiatry, Hanyang University Guri Hospital, 153 Gyeongchunro, Guri 11923, Republic of Korea

Tel: +82-31-560-2273, Fax: +82-31-554-2599, E-mail: jchoi@hanyang.ac.kr

(a) This is an Open Access article distributed under the terms of the Creative Commons Attribution Non-Commercial License (http://creativecommons.org/licenses/by$\mathrm{nc} / 3.0$ ) which permits unrestricted non-commercial use, distribution, and reproduction in any medium, provided the original work is properly cited. tracted by the varimax method. The number of factor in the solution was estimated on a scree plot, using eigenvalues $>1 .{ }^{6}$ In addition, only a loading $>0.40$ was considered to reveal a clear factor structure and content. As a result, Bartlett's test for sphericity was significant $\left[X^{2}(166)=468.72, p<0.001\right]$, and the total variance of the factor solution was $70.69 \%$. Table 1 gives the factor loadings for a three-factor solution. The first factor consists of the domains for delusions, hallucinations, disorganized speech and abnormal psychomotor behavior, and is designated "positive/speech". The second factor consists of the domains for negative symptoms and impaired cognition, and is named "negative/cognition". The third factor consists of the domains for depression and mania, and is designated "depression/mania". In addition, Pearson's correlations between the factor scores on the CRDPSS and the total and subscale scores on other measurement tools were obtained. Scores on the positive/speech factor were significantly correlated with scores on the positive symptoms subscale [Brief Psychiatric Rating Scale (BPRS)] ${ }^{7}(\mathrm{r}=0.81, \mathrm{p}<0.01)$, negative symptoms subscale $(B P R S)^{7}(r=0.62, p<0.01)$, resistance subscale $(B P R S)^{7}(r=0.44, p<0.01)$, Scale for the Assessment of Thought, Language and Communication (TLC scale) ${ }^{8}$ $(\mathrm{r}=0.64, \mathrm{p}<0.01)$, Calgary Depression Scale for Schizophrenia $(\mathrm{CDSS})^{9}(\mathrm{r}=-0.32, \mathrm{p}<0.01)$, Young Mania Rating Scale $(\mathrm{YMRS})^{10}$ $(\mathrm{r}=0.58, \mathrm{p}<0.01)$ and Clinical Global Impression of severity $(\mathrm{CGI}-\mathrm{S})^{11}(\mathrm{r}=0.85, \mathrm{p}<0.01)$. Scores on the negative/cognition factor were correlated with scores on the negative symptoms subscale (BPRS) $(\mathrm{r}=0.35, \mathrm{p}<0.01)$, resistance subscale (BPRS) $(\mathrm{r}=0.38, \mathrm{p}<0.01)$, TLC scale $(\mathrm{r}=0.40, \mathrm{p}<0.01)$ and CDSS $(\mathrm{r}=$ $0.17, p=0.03$ ), and scores on the depression/mania factor were correlated with scores on the psychological discomfort subscale $(B P R S)^{7}(r=0.25, p<0.01)$, the CDSS $(r=0.17, p<0.01)$ and the YMRS $(\mathrm{r}=0.81, \mathrm{p}<0.01)$.

Our investigation has the virtue of pioneering research into the evaluation of patients with schizophrenia using the CRDPSS. 
Table 1. Three-factor solution of the CRDPSS $(\mathrm{N}=166)$

\begin{tabular}{llccc}
\hline \multicolumn{1}{c}{ Factor } & \multicolumn{1}{c}{ Item } & Loading & Eigenvalue & \% variance \\
\hline Positive/Speech & II. Delusions & 0.88 & 2.78 \\
& I. Hallucinations & 0.81 & \\
& III. Disorganized speech & 0.76 .77 \\
& IV. Abnormal psychomotor behavior & 0.69 & \\
Negative/Cognition & V. Negative symptoms & 0.82 & 1.78 \\
Depression/Mania & VI. Impaired cognition & VII. Depression & 0.77 & 1.09 \\
& VIII. Mania & 0.85 & 0.60 & 13.65 \\
\hline
\end{tabular}

CRDPSS: Clinician-Rated Dimensions of Psychosis Symptom Severity

In summary, it shows that the 8-domain CRDSS has a threefactor structure, consisting of positive/speech, negative/cognition and depression/mania factors. Pearson's correlations indicate that all three factors have favorable concurrent and divergent validity. Hence, our findings shed light on the heterogeneous symptom components of schizophrenia.

\section{Acknowledgments}

This research was supported by the 2015 Research Fund of the Korean Society for Schizophrenia Research.

\section{REFERENCES}

1. Barch DM, Bustillo J, Gaebel W, Gur R, Hecker S, Malaspina D, et al. Logic and justification for dimensional assessment of symptoms and related clinical phenomena in psychosis: relevance to DSM-5. Schizophr Res 2013;150:15-20.

2. Heckers S, Barch DM, Bustillo J, Gaebel W, Gur R, Malaspina D, et al. Structure of the psychotic disorders classification in DSM-5. Schizophr Res 2013;150:11-14.

3. Parnas J. DSM-IV and the Founding Protype of Schizophrenia: Are We Regressing to a Pre-Kraepelinian Nosology? In: Kendler KS, Parnas J, Editors. Philosophical Issues in Psychiatry II: Nosology. Oxford:
Oxford University Press, 2012, p.237-259.

4. Park SC, Jang EY, Lee KU, Lee K, Lee HY, Choi J. Reliability and validity of the Korean version of the scale for the assessment of thought, language, and communication. Compr Psychiatry 2015;61:122-130.

5. American Psychiatric Association. Diagnostic and Statistical Manual of Mental Disorders, 5th Edition. Washington, DC: American Psychiatric Association; 2015.

6. Kaiser HE. The application of electronic computers to factor analysis. Educ Psychol Meas 1960;18:667-683.

7. Lachar D, Bailley SE, Rhoades HM, Espadas A, Aponte M, Cowan KA, et al. New subscales for an anchored version of the brief psychiatric rating scale: construction, reliability, and validity in acute psychiatric admission. Psychol Assess 2001;13:384-395.

8. Andreasen NC, Grove WM. Thought, language, and communication in schizophrenia: diagnosis and prognosis. Schizophr Bull 1986;12: 348-359.

9. Addington D, Addington J, Schissel B. A depression rating scale for schizophrenia. Schizophr Res 1990;3:247-251.

10. Young RC, Biggs T, Ziegler VE, Meyer DA. A rating scale for mania: reliability, validity, and sensitivity. Br J Psychiatry 1978;133:429-435.

11. Haro JM, Kamath SA, Ochoa S, Novick D, Rele K, Fargas A, et al. The Clinical Global Impression-Schizophrenia scale: a simple instrument measure the diversity of symptoms present in schizophrenia. Acta Psychiatr Scand Suppl 2003;(416):16-23. 